\title{
A Review on Production of Exopolysaccharide and Biofilm in Probiotics Like Lactobacilli and Methods of Analysis
}

\author{
Pegah Hooshdar ${ }^{1}$, Rouha K. Kermanshahi ${ }^{1}$, Parinaz Ghadam ${ }^{2}$, Kianoush Khosravi-Darani ${ }^{3}$, (1) \\ 1 Department of Microbiology, Faculty of Biological Sciences, University of Alzahra, Tehran, Iran \\ 2 Department of Biotechnology, Faculty of Biological Sciences, University of Alzahra, Tehran, Iran \\ 3 Department of Food Technology Research, National Nutrition and Food Technology Research Institute, Faculty of \\ Nutrition Sciences, and Food Technology, Shahid Beheshti University of Medical Sciences, P. O. Box 19395-4741, Tehran, \\ Iran \\ * Correspondence: k.khosravi@sbmu.ac.ir;
}

Scopus Author ID 23969408200

Received: 15.02.2020; Revised: 25.04.2020; Accepted: 28.04.2020; Published: 1.05.2020

\begin{abstract}
Synthesis of exopolysaccharides (EPSs) by lactic acid bacteria is well known and the EPS produced by Lactobacillus has been highly regarded in recent years because of its unique physical and chemical application in the food and pharmaceutical industry. One of the capabilities of probiotics is the use of EPS to form a biofilm produced in tense environments. In this paper after a short description about EPS, the reason for production in bacterial cells, and its biosynthesis pathways; the capability of Lactobacilli for EPS and biofilm formation are reviewed. The chemical composition of EPS, its role in the bacterial life cycle as well as applications for humankind have been studied. Then the important components in biofilm formation are described and variable influencing on biofilm formation (surface, bacterial cell surface, contact time and environmental characteristics) are reviewed. The relationship between EPS and extracellular polymeric precursors as well as the relationship between biofilm formation and EPS production are mentioned. Finally, methods for quantification of carbohydrate (enzymatic, physical, chemical methods), biofilm formation and EPS extraction (Tallon and Bajpai methods) are reviewed and advantages of methods are compared. EPSs produced by probiotics is important due to the application as a thickening agent, emulsifier, heavy metal eliminator, and drug delivery carrier. Also, it has been considered for its anti-cancer, anti-viral, and cholesterol-lowering properties. So forming biofilm by some probiotics in simple and mixed culture are discussed, the relationship between EPS and biofilm production are discussed. When probiotics produce biofilm, they can be more tolerated in the processing of food production and in the gastrointestinal tract. So the efficacy of probiotic transfer may increase by a self-protection potency without any required encapsulation processing, solvent residue, time and energy consumption, etc. Also, identification and measurement methods are reviewed and compared.
\end{abstract}

Keywords: Probiotic; Lactic acid producing bacteria; Exopolysaccharide; Capsule; Biofilm formation.

(C) 2020 by the authors. This article is an open access article distributed under the terms and conditions of the Creative Commons Attribution (CC BY) license (https://creativecommons.org/licenses/by/4.0/).

\section{Introduction}

Probiotics that confer health beneficial impacts to the host, when administered in adequate amounts. Some of them can also, can be considered as a suitable way for bioremoval of pollutants including toxins, heavy metal $\left(\mathrm{Pb}^{2+}, \mathrm{Cr}^{2+} / \mathrm{Cr}^{3+}, \mathrm{Cd}^{2+}, \mathrm{Zn}^{2+}, \mathrm{Cu}^{2+}, \mathrm{Hg}^{2+}\right.$ etc.), residues, etc. from water and foodstuff [1-6]. Antimicrobial activities of synbiotic extract could 
differ in their antagonistic activities against diarrhoeal causing organism which could be due to the metabolite secreted by the lactic acid bacteriocin especially the type of organic acids and added inulin as a prebiotic and for food preservation [7].

\section{Exopolysacchride}

Exopolysaccharides (EPSs) of lactic acid bacteria (LAB) adhere closely to the bacterial surface with covalent bonds which may be released into the surrounding medium or attached loosely to bacterial cells. EPS as high molecular weight polymers made up of sugar substitutes are divided into two groups: hemopolysaccharides and heteropolysaccharides. The EPS produced by lactobacilli has been highly regarded in recent years because of its unique physical and chemical properties in the food industry as a viscosity, jelly, thickener, emulsifier, heavy metals removal.

In the pharmaceutical industry, as agents for the transfer of drugs and in the field of therapeutic anticancer, antiviral, anti-inflammatory, and the property of lowering blood cholesterol. One of the capabilities of probiotics is the use of EPS to form a biofilm that is produced by a number of its isolates in tense environments $[8,9]$.

\section{EPSS biosynthesis pathways}

Two separate mechanisms have been identified for biosynthesis of EPS. Homopolysaccharides are synthesized via extracellular mechanisms by enzymes secreted to the cell exterior, while heteropolysaccharides are produced via more complex mechanisms. Precursors of EPSs are firstly produced in cytoplasm and then the other stages of the biosynthesis take place outside the cells. Synthesis of EPSs by bacteria employs a broad spectrum of enzymes that are not specific and unique to the production of EPSs.

Nucleotide diphosphate sugars as an active form of monosaccharides, provide various types of active monosaccharides for microbial cells via epimerization, dehydrogenation, and decarboxylation reactions. Isoprenoidglycosyl lipid carriers have a role in their synthesis [8]. Enzymes involved in the synthesis of EPSs can be divided into four groups: 1) enzymes involved in internal carbohydrate metabolism, 2) enzymes involved in producing nucleotide sugars and in converting them into each other, 3) glycosyltransferases that shape repeating units and attach them to glycosyl lipid carriers, and 4) enzymes involved in polymerization and translocation of carbohydrates [9].

\section{EPSS - producing labs}

Most EPS-producing LABs belong to the Streptococcus, Lactobacillus, Lactococcus, Leuconostoc, and Pediococcus Sps. Some strains of Bifidobacteria have also exhibited the ability to produce these polymers.

\subsection{Lactobacilli.}

These are Gram-positive catalase-negative bacteria of fermentative metabolism because they lack respiratory chains. Some are microaerophiles and others obligate anaerobes. There are more than 125 strains in the Lacobacillus Sp. [10].

Lactobacilli are commonly found in human and animal intestines, form a protective barrier against pathogenic bacteria, and exhibit antagonistic activities against the 
gastrointestinal tract diseases caused by bacteria of the Listeria, Salmonella, Shigella, and Klebsiella Sps. [11]. They also play a role in protecting the female urinary-genital tract with their antimicrobial activities against some pathogens like Proteus vulgaris [12].

Although Gram-positive bacteria also produce EPSs, the main producer of EPSs are LABs. EPS producing LABs are isolated from dairy and non-dairy products under various conditions by adding various types of sugar [13].

\section{Chemical composition of EPSS produced by labs}

Researchers reached the general consensus that the EPSs present in lactic acid producing bacteria were polysaccharides consisting of repeating (branched) units that included $\alpha$ and $\beta$ bonds and were secreted in various types although their monomeric constituents were clearly similar to each other. For example, L. acidophilus LMG 9433 and L. rhamnosus C83 have lost their rhamnose, or L. sake 0-1 only has glucose and rhamnose. The use of complicated compounds in culture media causes production of various types of EPSs. This indicates that the types of EPSs vary under different conditions [14].

\section{Various EPSS in bacteria producing them}

The gene producing EPSs in mesophilic Lactobacilli is a plasmid that may be lost due to its instability, but thermophilic Lactobacilli have a gene cluster for EPS production which they delete under unstable conditions or transmit as mobile elements. Various types of heteropolysaccharides with different molecular weights and component sugars are secreted by mesophilic and thermophilic Lactobacilli. In general, thermophilic LABs produce more heteropolysaccharides compared to mesophilic LABs [13].

\section{The role played by microbial EPSS}

In the natural environment of microbial life, EPSs play an important role in protecting microbial cells against water loss and drying, phagocytosis, phages, antibiotics, toxic compounds like toxic metallic ions, sulfur dioxide and ethanol, protozoan predators, and osmotic stress, and in helping microbial cells to adhere to solid surfaces, form biofilms, and recognize cells (through binding to a lectin). The important point is that bacteria do not use EPSs as a food source because most bacteria producing EPSs lack the ability to catabolize them. Capsular EPSs and lipopolysaccharide O-antigen play a role in the response of the host immune system to pathogenic bacteria like Streptococcus agalactiae [14, 15].

\subsection{EPSs applications.}

The important microbial EPSs in industry are dextran, gellan, xanthan, pullulan, alginate, and glucan produced by yeast. New microbial biopolymers can satisfy the unmet needs in the industry [14]. Bacterial EPSs are used to remove heavy metals [14, 16].

EPSs also has various applications in pharmaceutical industries like coating material for drugs [17]. In medicine, they are utilized for their mentioned health-promoting effects. They are used in the food industry for fermentation in food processing. EPSs are utilized in the food industry to improve rheological properties, provide consistency, increase viscosity, and enhance the taste of food materials [18]. They are also used in the food industry to produce lower fat and higher quality dairy products [13]. 
The high-molecular-weight homopolysaccharide dextran produced by LABs has antiviral properties and enhances the immune system of aquatic organisms. The EPS produced by Leuconostoc mesenteroides RTF10, Lactobacillus sakei MN1 is utilized as fish feed [19].

\section{Biofilm}

Formation of bacterial biofilms is in fact stages in the life of bacteria that start with their attachment to a surface [20]. Biofilms are complex bacterial communities attached to surfaces that are created by the extracellular matrix that the bacteria produce. This matrix consists of EPSs, nucleic acids and proteins. Bacterial biofilms can protect bacteria against environmental stresses, the immune response of the host, antimicrobial agents and antibiotics [21, 22]. Bacterial biofilms were discovered in the late $17^{\text {th }}$ century.

Using a rudimentary microscope, Antony van Leeuwenhoek showed the presence of small particles (called animalcules) on the surfaces of teeth. A group of bacteria joined to each other and adhered to a surface were then studied in 1934. In general, biofilm construction includes initial attachment of bacteria to a surface, production of extracellular polymers the most important of which are the EPSs, formation of a microcolony and growth and maturity and, finally, dispersion of some of the bacteria [23-25]. Fig 1. presents the process of the formation of a biofilm.

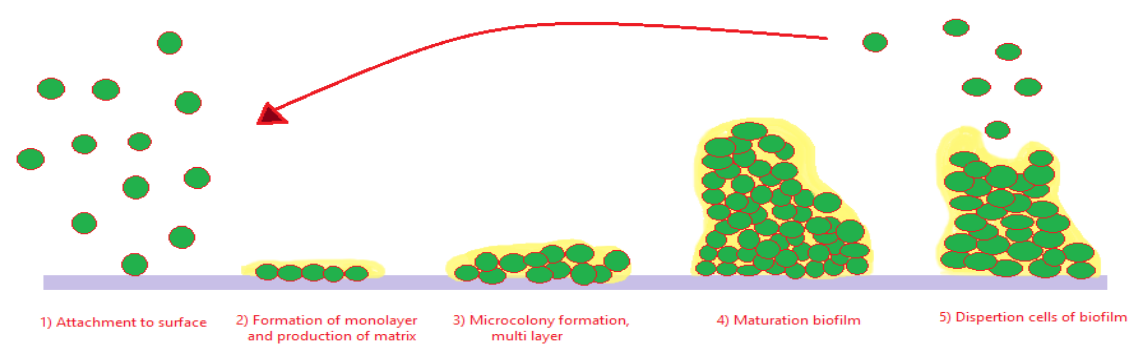

Figure 1. The process of biofilm formation.

\subsection{The important components in biofilm formation.}

Biofilm construction depends on the interaction between the four main components of bacterial cells, surface attachment, the surrounding environment, and the contact time.

\subsubsection{Effects of the attachment surface.}

Surface features like roughness, cleanliness, and wettability (determined by hydrophobicity) are among the factors influencing adhesion of bacteria to surfaces [23].

\subsubsection{Bacterial cell surface properties.}

Cell physical and chemical properties including electrical charge of bacterial cell surface, which is related to the presence of acid groups like carboxyl, phosphate and basic groups such as the amines present on cell surface, play a role in the attachment of bacterial cells to a surface. Cell surface appendages like pili, flagella, and surface polysaccharides also play an important role in bacterial attachment [23].

\subsubsection{Environmental characteristics.}

These characteristics, which are among the effective factors for bacterial attachment, include the hydrodynamic conditions of the environment, the physical and chemical properties 
of the environment including the $\mathrm{pH}$ of the surface, nutrients, ionic power, and temperature [25].

\subsubsection{Contact time.}

Contact time between bacteria and the surface is an important factor for the establishment of an irreversible attachment. It has been proved that increases in contact time improve the strength of the attachment to the surface Factors influencing biofilm maturity include dissolved oxygen concentration, carbon source, osmotic pressure, and $\mathrm{pH}$ of the environment. Biofilm formation is a complex process controlled by various bacterial genes including those related to expression of quorum-sensing signals [26].

\subsection{Biofilm construction by probiotic Lactobacilli.}

One of the useful abilities of probiotic Lactobacilli is forming biofilms for protecting themselves against environmental stresses and for helping their colonization and population maintenance [27].

Probiotics form complex communities known as biofilms and have several useful properties for developing microbial populations under biotic or abiotic condition [20]. It must be mentioned that biofilm formation in the digestive system requires effective attachment to epithelial cells, effective attachment time, and stabilization of the bacteria on epithelial cells.

These cells then prevent the competitive attachment of pathogenic bacteria and forming biofilm, also they can stimulate the host immune system [28].

Studies have been conducted so far on biofilms of probiotic Lactobacilli like $L$. rhamnosus, L. plantarum, L. fermentum, and L. reuteri. One of the components that participate in adhesion and biofilm formation is S-layer. It being a protective sheath against hostile environmental agents and having an important role in the establishment of Lactobacillus acidophilus in the gastrointestinal tract. The Stability of this part of microbial cells was examined in different conditions [29, 30].

Another area of interest in research on probiotics is using them for coating bacteria. For example, there is a hypothesis stating that this coating makes it possible to add probiotics to some food materials, allows the probiotics to remain stable over time, prevents them from reacting with food constituents, and enables them to resist gastric $\mathrm{pH}$ when attached to the intestines. These are achieved because small amounts of a specific probiotic are coated with polymeric materials to protect them against factors like heat, moisture, freezing, and gastric $\mathrm{pH}$. Therefore, these coated probiotic bacteria survive and reach the main location where attach to the intestines [24].

In recent years, use of probiotic plankton cells for coating has been limited and utilization of fourth generation probiotics (that is, making use of their biofilm shape with a double-layer protective coating) is a new and attractive area that has attracted the interest of researchers in recent years [31].

\subsection{The relationship between EPS and extracellular polymeric precursors.}

Extracellular polymeric precursors, which are produced by LABs to construct biofilms, include a set of glycoproteins, nucleic acids, phospholipids, and polysaccharides, especially EPSs [32]. One of the components existing in the outer layer of bacteria, besides EPSs is S-layer that protect bacteria against some environmental risk [31]. 
8.4. Biosynthetic pathways of extracellular polymeric precursors in probiotic Lactobacilli and factors influencing their production.

Synthesis of extracellular polymeric precursors serves several functions: it causes microbial attachment to the solid surface, the formation of a microcolony, and maturity of the biofilm structure in addition to making the biofilm resistant to environmental stresses and to disinfectants. In some cases, the matrix of extracellular polymeric precursors enables the bacteria to obtain a series of their required food materials. Production of extracellular polymeric precursors for attachment of microorganisms is a complex process influenced by various factors; in addition, the processes involved in biofilm development are different in the various species [33].

\subsubsection{Extracellular polymeric precursors.}

In general, the matrix containing the polymeric precursors is $0.1-1 \mu \mathrm{m}$ thick. In some bacterial species its thickness is $10-430 \mathrm{~nm}$ and the matrix is not very valuable. The chemical structures of the polymeric materials secreted by bacterial cells into the environment are varied $[20,21]$. Constituents of extracellular precursors differ even within a bacterial species. Most external microbial layers include neutral carbohydrates (hexane the most and pentane the least prevalent) and uric acid. The most common extracellular carbohydrate constituents are acetate, pyruvate, fumarate, and succinate esters. The presence of polypeptides in the matrix of extracellular polymeric precursors is specific to a limited number of Gram-positive species. Polysaccharides and proteins are the most widely studied constituents present in the layer of extracellular polymeric precursors [34]. The structures of the polysaccharides produced by microbial cells are very different with respect to the types of bonds. This is observed in the case of microbial cells belonging to the Streptococcus, Leuconostoc, and Sinorhizobium Sp. Microbial EPSs have been compared with respect to being homopolysaccharides or heteropolysaccharides. Homopolysacchar-ides only contain one type of monosaccharide (Dglucose or L-fructose). Homopolysaccharides are divided into the following three groups:

A-D-glucans: These are produced by Leuconostoc mesenteroides. The constituents among the D-glucosyl units mostly include $\alpha(1 \rightarrow 6)$ bonds. The branches are mainly in the form of $\alpha(1 \rightarrow 3)$ and less frequently in the forms of $\alpha(1 \rightarrow 2)$ and $\alpha(1 \rightarrow 4)$.

$B$-D-glucans: These are mostly produced by the Pediococcus and Streptococcus genera. The D-glucosyl units are connected by $\beta(1 \rightarrow 3)$ bonds and the branches by $\beta(1 \rightarrow 2)$ bonds.

Fructans: These are mainly produced by the species Streptococcus salivarius. The fructosyl units are connected by $\beta(2 \rightarrow 6)$ bonds.

A number of LABs produce heteropolysaccharides. These molecules are formed from repeating monosaccharide units such as D-glucose, D-galactose, L-fructose, L-rhamnose, Dglucuronic acid, L-guluronic acid, and D-mannuronic acid.

The types of both bonds between monosaccharide units and chain branches determine the type of the heteropolysaccharide. The most frequently found heteropolysaccharides include pyruvate, succinate, and fumarate sub-units. Bacterial alginate is an insoluble heteropolysaccharide with D-mannuronosyl and L-guluronosyl at its two ends. Alginate is mostly produced by Pseudomonas aeruginosa and Azotobactervinelandii. The secreted extracellular proteins have molecular weights of 10-200 kDa. These constituents include 4060 percent of hydrophobic amino acids [32]. 


\subsection{Physiological study of extracellular polymeric precursors.}

Synthesis of extracellular biopolymers by microbial cells depends on the presence of carbon and nitrogen in the culture medium. Most extracellular polymers of microorganisms are produced using carbohydrates as the carbon source and ammonium salts and amino acids as the nitrogen source. In general, production of extracellular polymeric precursors increases under conditions where the largest amounts of glucose are present in the environment. Synthesis of extracellular constituents in Acetobact-erxylinum takes place with access to fructose, sucrose, and starch at concentrations of 25-100 g/L. The lowest production level of precursors is observed under conditions where lactose and xylose are present. Carbohydrates like xylose, ribose, sucrose, lactose, glucose, fructose, and mannose are the precursors required for the production of these extracellular precursors. Moreover, low nitrogen content in the culture medium greatly increases synthesis of extracellular biopolymers [32].

\subsection{Molecular features related to synthesis of extracellular polymeric precursors.}

The mechanisms regulating production of extracellular polymeric precursors have not been completely determined yet. Shaping the production process of the precursors requires enzymes. Each enzyme, produced by the gene related to the synthesis of extracellular polymeric precursors, is responsible for carrying out a separate part of the process. Tang et al. (1990) showed that a region of the Xanthomonascampestris genome (the rpf gene cluster) produces both the extracellular polymeric molecules and the enzymes that control their production (and are involved in the transmission process). Under abnormal conditions, microorganisms undergo changes in taxonomy and produce a collection of extracellular materials. These changes are observed in Pseudomonas aeruginosa [32, 35].

\subsection{The relationship between biofilm formation and EPS production.}

One of the abilities of probiotics is using EPSs as one of the important constituents of extracellular polymeric precursors utilized in biofilm construction.

Salas-Jara et al. (2016) extracted the EPSs from L. fermentum CO-979 and investigated its biofilm construction. They also used $L$. caseiShirota as the control and made some changes in the Tallon method to extract the EPSs. After studying the biofilms of L. fermentumUCO979 and L. caseiShirota, they found that stronger biofilms were formed in the isolates with the passage of time. Finally, they measured the amounts of extracted EPSs at different times and noticed that there was a relationship between the quantities of extracted EPSs and biofilm construction [24].

Results obtained by Verhoeven et al. (2007) indicated that glucose was the initial raw material for producing EPSs, it was the most important part of the biofilm matrix, and the efficiency of producing EPS production and biofilm construction changed with changes in the quantity of glucose [15].

Branda et al. (2005) stated that the presence of EPSs played a vital role in biofilm expansion [19]. Moreover, Lebeer et al. (2007) cultured L. rhamnosus GG in media containing various compounds to show a linear relationship between biofilm construction and EPS production [17]. They extracted the EPSs in the stationary phase and studied their biofilms at the same time. It was found that stronger biofilms were formed in the culture media in which more quantities of both capsular EPSs and EPSs released into the medium were produced. They concluded environmental factors and culture media played a substantial role in biofilm 
construction and, consequently, in the production of EPSs in L. rhamnosus GG, and also noticed that the effect of EPSs on biofilm formation was dependent on the culture media. For example, the largest amounts of EPSs were produced in the AOAC culture media whereas the best biofilm shapes were observed in the mTSB culture medium. Therefore, they reached the conclusion that the size, chemical structure, and location of EPSs and surface features were involved in the attachment of the bacteria.

Vasquez et al. (2017) demonstrated that the EPS dextran produced by L. sakei MN1 was an anti-microbial attachment factor and prevented biofilm formation in this species, whereas the same EPS did not affect biofilm construction in L. mesenteroides RTF10. In addition, OlayaRendueles et al. (2013) showed that a polysaccharide named A101 prevented activity and development of biofilms $[19,36]$.

\section{Methods}

\subsection{Mixed probiotic cultures.}

Many bacterial species including pathogenic bacteria become more resistant to extracellular stressful conditions by constructing biofilms consisting of two or more bacterial species. To prepare probiotic cultures, the turbidity of each isolate was adjusted to that of a 0.5 McFarland standard, $100 \mu \mathrm{l}$ of each isolate was poured into each well of the microplate so that there was $200 \mu l$ of the two bacterial suspensions in each well. The biofilm was then stained with crystal violet ( $2 \mathrm{~g}$ of crystal violet dye was dissolved in $10 \mathrm{ml}$ of ethanol absolute, and the solution was passed through Whatman filter paper and was raised to volume using $90 \mathrm{ml}$ of distilled water). After decolorization by acetic acid, absorbance was read at $492 \mathrm{~nm}$ using an ELISA plate reader [37].

\subsection{Methods for carbohydrate analysis and quantitative assessment of carbohydrates.}

Nowadays identifying structures of oligosaccharides has a special role in biological research and is an important factor for making advances in analysis [38].

\subsubsection{Enzymatic methods.}

Enzyme-based analytical methods have the ability for specialized reactions. These specialized reactions are rapid and accurate and detect even low carbohydrate concentrations. Many enzymatic kits are available and are used for specialized diagnostic tests.

\subsubsection{Physical methods.}

Various physical methods have also been developed for quantitative assessment of carbohydrates. These methods make changes in the physicochemical characteristics of carbohydrates present in a sample. Polarimetry, IR, refractive index, and density are among these methods.

\subsubsection{Chemical methods.}

These are based on reactions between sugars and other compounds that result in changes in color or sedimentation. Concentrations of the carbohydrates are then obtained based on measuring density, using spectrophotometric methods, and titration. There are various 
methods for measuring concentrations of carbohydrates [39]. Table 1.presents chemical methods for sugar assessment.

\subsection{The phenol-sulfuric acid method.}

Analysis of oligosaccharides is very complicated because, unlike proteins and nucleic acids, a number of them are branched and use various types of bonds to bind to other substances. The high charge density in oligosaccharides and polysaccharides and the sulfate esters in them add to the difficulty. Hydrolysis of oligosaccharides and polysaccharides in strong acids produces a mixture of monosaccharides. Quantitative chromatography methods are used to identify these monosaccharides in order to determine the general composition of the polysaccharide polymers. NMR spectroscopy provides extensive information on polymers and on configurations of anomeric carbons.

Colorimetric assays for reducing sugars and polysaccharides have been used for a long time. Simple sugars, oligosaccharides, polysaccharides and their derivatives including methyl ethers have (or potentially have) free oxidizing agents that produce a yellow-orange color when treated with phenol and concentrated sulfuric acid. This is a very sensitive reaction and the produced color is stable. The phenol-sulfuric acid method is a suitable method for assessing carbohydrates and their related derivatives [40].

This method was first developed by Dubois et al. in 1956 to determine the total concentrations of sugars and their derivatives in which simple sugars (monosaccharides), oligosaccharides, and their derivatives like methyl ethers react with free reducing agents. The color produced in these reactions remains stable for several hours. Therefore, this method determines the total carbohydrate content. It is not a stoichiometric method and requires a standard curve drawn by using known concentrations of a carbohydrate.

The total extracted carbohydrates in the various methods were used in the phenolsulfuric acid method to draw the standard curve for glucose. In this method, first $250 \mu 1$ of $5 \%$ phenol and then $1,250 \mu \mathrm{l}$ of concentrated sulfuric acid were added to $0.5 \mathrm{ml}$ of the extracted EPS solution. After 10 minutes the solution was vortexed for 30 seconds and, 20 minutes later, absorbance was read at 490nm. In this experiment, a two-phase system is first formed after the addition of phenol and sulfuric acid. However, a uniform orange color is produced after the solution is vortexed [40]. Here, the control sample consists of $300 \mu 1$ water $+250 \mu 15 \%$ phenol+ $1,250 \mu 1$ concentrated sulfuric acid.

\subsection{Application of trichloroacetic acid.}

Trichloroacetic acid (TCA), which is usually used to precipitate proteins, precipitates them irrespective of their physico-chemical conditions, but it is not able to precipitate unfolded proteins. TCA causes proteins to precipitate by dehydrating the hydration shells around them. Other studies also indicated that TCA changed protein conformations and precipitated them due to its acidic property. However, the exact mechanism of this precipitation is not completely clear. Protein precipitation by TCA is somewhat reversible. In general, protein precipitation takes place in one of the following three classes:

Phase 1: This happens at concentrations less than 5\% w/v of TCA. Increases in acid concentration advances protein precipitation. 
Phase 2: This happens at concentrations of $5-45 \% \mathrm{w} / \mathrm{v}$ of TCA. The largest amount of precipitation happens in this concentration range, and higher concentrations reduce the quantity of precipitated proteins.

Phase 3: This happens at concentrations higher than $45 \% \mathrm{w} / \mathrm{v}$ of TCA. Protein precipitation markedly decreases at $45 \% \mathrm{w} / \mathrm{v}$ and no precipitation, or very little precipitation, happens at $60 \% \mathrm{w} / \mathrm{v}$ of TCA. The noteworthy point is that the amount of protein precipitation is independent of protein concentration at all concentrations of TCA. Results were obtained using SDS-PAGE and reading absorbance at $290 \mathrm{~nm}[41,42]$.

Table 1. Chemical methods for determination of sugars

\begin{tabular}{|c|c|c|c|c|c|}
\hline Technique & Description & Absorbance & Advantages & Defects & Color regent \\
\hline $\begin{array}{l}\text { 1.Dinitrisalicyli } \\
\text { c acid (DNS) }\end{array}$ & $\begin{array}{l}\text { This method estimates } \\
\text { the quantity of } \\
\text { reducing sugar in the } \\
\text { sample }\end{array}$ & $570 \mathrm{~nm}$ & $\begin{array}{c}\text { Suitable for } \\
\text { assessment of } \\
\text { simple sugars like } \\
\text { glucose, fructose, } \\
\text { etc. }\end{array}$ & $\begin{array}{c}\text { Not suitable for } \\
\text { assessing complex } \\
\text { sugars like various } \\
\text { polymers and } \\
\text { polysaccharides }\end{array}$ & $\begin{array}{l}\text { DNS changes } \\
\text { the yellow color } \\
\text { into orange }\end{array}$ \\
\hline 2.Anthrone & $\begin{array}{l}\text { This method uses } \\
\text { diluted hydrochloric } \\
\text { acid to convert glucose } \\
\text { to inert } \\
\text { hydroxymethylfurfural }\end{array}$ & $630 \mathrm{~nm}$ & $\begin{array}{l}\text { Very sensitive for } \\
\text { assessment of } \\
\text { glucose }\end{array}$ & $\begin{array}{c}\text { Not suitable for } \\
\text { assessing complex } \\
\text { sugars like various } \\
\text { polymers and } \\
\text { polysaccharides }\end{array}$ & $\begin{array}{l}\text { Anthrone creates } \\
\text { a green color in } \\
\text { the environment }\end{array}$ \\
\hline $\begin{array}{l}\text { 3.The phenol- } \\
\text { sulfuric acid } \\
\text { method }\end{array}$ & $\begin{array}{l}\text { This method uses } \\
\text { concentrated sulfuric } \\
\text { acid to break down } \\
\text { sugars into simpler } \\
\text { units and employs } \\
\text { phenol as the color } \\
\text { reagent }\end{array}$ & $490 \mathrm{~nm}$ & $\begin{array}{l}\text { Suitable for } \\
\text { assessment of all } \\
\text { carbohydrates, } \\
\text { monosaccharides, } \\
\text { disaccharides, and } \\
\text { polysaccharides }\end{array}$ & $\begin{array}{l}\text { Since the toxic } \\
\text { material phenol is } \\
\text { used in this method, } \\
\text { care must be } \\
\text { exercised in waste } \\
\text { disposal }\end{array}$ & $\begin{array}{l}\text { Phenol creates a } \\
\text { yellow color in } \\
\text { the environment }\end{array}$ \\
\hline $\begin{array}{l}\text { 4. The Nelson- } \\
\text { Somogyi } \\
\text { method }\end{array}$ & $\begin{array}{l}\text { This method estimates } \\
\text { the quantity of } \\
\text { reducing sugar in the } \\
\text { sample }\end{array}$ & $500 \mathrm{~nm}$ & $\begin{array}{c}\text { Suitable for } \\
\text { assessment of } \\
\text { simple sugars like } \\
\text { glucose, fructose, } \\
\text { etc. }\end{array}$ & $\begin{array}{c}\text { Not suitable for } \\
\text { assessing complex } \\
\text { sugars like various } \\
\text { polymers and } \\
\text { polysaccharides }\end{array}$ & $\begin{array}{l}\text { Arsenomolybdic } \\
\text { acid creates a } \\
\text { blue color in the } \\
\text { environment }\end{array}$ \\
\hline
\end{tabular}

\subsection{Measurement of biofilm formation in microtiterplates.}

Microbial biofilms have been studied for several decades. A set of methods have been developed for culturing and studying biofilms but there is no standard method for investigating biofilms of various bacterial species. At first, biofilms were measured by culturing bacteria inside tubes and by examining biofilm formation on the biofilm walls. Nowadays, various methods like test tubes, microplate test, radioactive labeling, microscopic methods, and Congo red agar plate test are used in studying biofilms. However, one of the most widely-used methods is the microplate test. The process of biofilm formation starts with the initial attachment of bacteria to the surface that is influenced by various factors like surface features, and the turbidity caused by the biofilm is directly related to the incubation period [43]. Many studies have pointed to 2 and others to 3-4 wash cycles. In the study conducted on the number of wash cycles, it was concluded that 3 wash cycles were more effective.

The microplate method is a colorimetric one currently used in most microbiology laboratories. It requires a very low volume of culture medium. In the method developed by Shakeri and Mahdavi, a single colony of the agar culture medium of the tested probiotic Lactobacilli was removed and cultured on MRS broth to prepare the primary culture. This culture was incubated for $24 \mathrm{~h}$ at $37^{\circ} \mathrm{C}$. A microbial suspension with the turbidity adjusted to that of a $0.5 \mathrm{McF}$ arland standard was then prepared, and $200 \mu \mathrm{l}$ of each isolate was poured into each well. The control wells contained only the sterile medium. The wells were made of 
polystyrene. The microplate was incubated for 18,24 , and $48 \mathrm{~h}$ at $37^{\circ} \mathrm{C}$ under anaerobic conditions (incubation conditions in $5 \% \mathrm{CO}_{2}$ ).

The contents of the wells were then emptied and the wells were washed three times with sterile physiological serum to remove all planktonic cells. The microplate was given time to dry. In the next stage, $200 \mu$ l of $2 \%$ violet crystal was added to each well and kept in it for 5 min. Violet crystal can stain biofilms and is used to assess them. The wells were then washed with sterile distilled water. A purple halo was observed in each well. For the quantitative analysis of biofilm construction, 33\% glacial acetic acid (v/v) was added to the wells, the plate was shaken several times, and absorbance was read at $492 \mathrm{~nm}$ using an ELIZA plate reader [44].

To report the results, the OD values of the samples were compared with that of the control (OD c):
$\mathrm{OD} \leq \mathrm{OD}_{\mathrm{c}}$
Biofilm was not formed
$\mathrm{OD} \leq 2 \times O D_{C}$
Weak biofilm
$2 \times O D_{c} \leq O D \leq 4 \times O D_{c}$
Average biofilm
$O D \geq 4 \times O D_{c}$
Strong biofilm

The same process was followed for the 24 and $48 \mathrm{~h}$.

\subsection{EPS extraction.}

There is a wide variety of methods for studying EPSs instead of a single comprehensive and complete one. This is because of diagnosis, isolation, and determination of the quantity of EPSs produced by microbial strains, the type of the employed culture medium, and also the accuracy level desired in the separation process influence the study methodology.

Some available methods require a very high speed of the centrifuge that may not be available to all researchers although it is an important factor in the separation efficiency of the ESPs produced by the bacteria. Moreover, TCA concentrations strongly influence extraction of the EPSs released into the medium. This type of EPSs has a much greater share than the capsular EPSs.

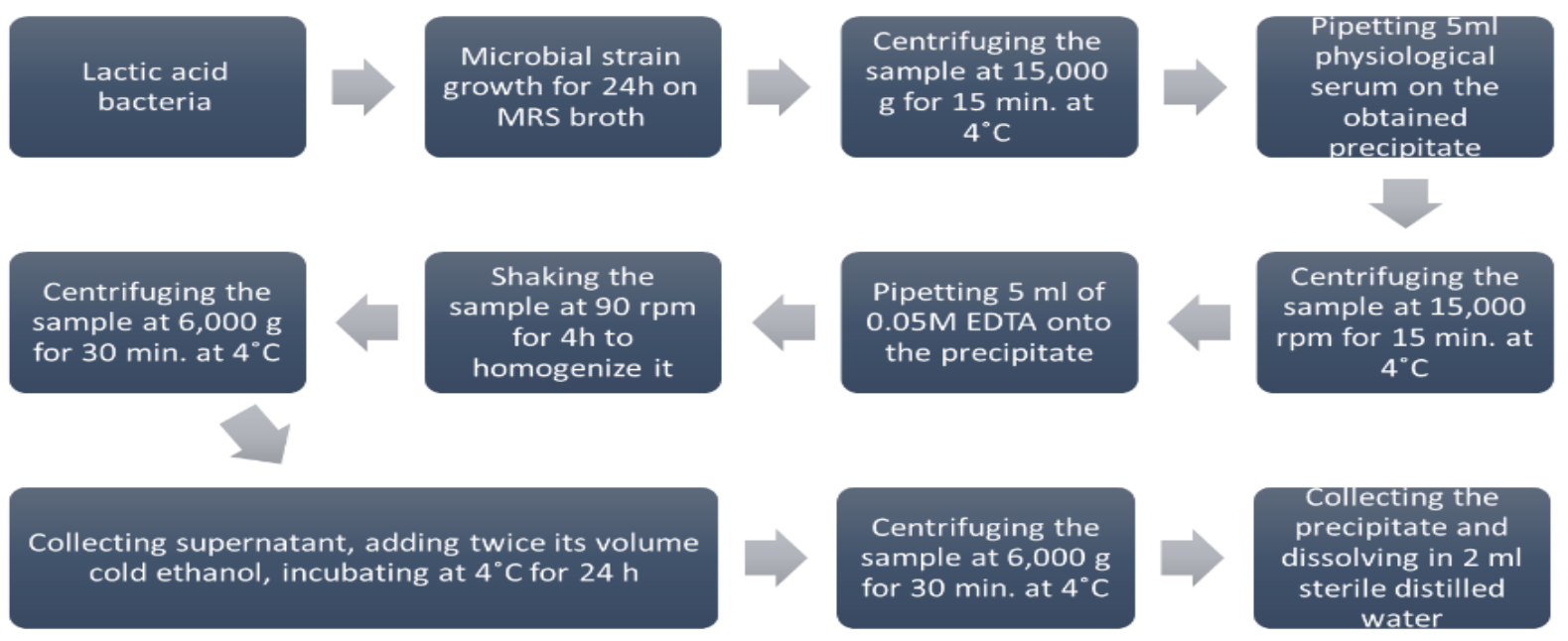

Figure 2. A summary of the Tallon method used to extract capsular EPSs.

Most separation methods of EPSs are time-consuming and tedious and there is the risk of losing polymer during the experiment, especially when the EPS is obtained from complex media. A broad spectrum of different methods has been published each different from the others. Various stages and different temperatures, use of centrifugation at different speeds, and 
employment of TCA, Pronase E, or trypsin for removing proteins, are just a few stages utilized in the methods based on precipitation of the EPS with ethanol [45].

According to research by Garcia-Garibay and Marshall (1991), Cerning et al. (1994), and Harding et al. (2003), precipitating protein with TCA is the most common method widely used for separating EPS from complex culture media. Proteins are precipitated using TCA and removed through centrifugation. The EPSs are then precipitated with ethanol. Precipitating with TCA for removal of unnecessary materials in the environment like proteins and peptides was first carried out by Garcia-Garibay and Marshall in 1991. The use of TCA recovers about $50 \%$ of the total produced EPSs. Furthermore, Stingele (1996), Lemoine (1997), De Vuyst et al. (1999) showed that precipitation with acetone instead of ethanol reduced the recovered ESPs from the total produced by about 5-10\% [14, 46, 47].

\subsubsection{The Tallon method.}

Tallon et al. (2003) purified the EPSs produced by L. plantarum EP56 for the first time and studied their biochemical properties [48]. This strain produces both capsular EPS and EPS released into the medium, and exhibits mucoid phenotype and ropy on MRS agar. A CDM culture medium is used to extract EPS from L. plantarum EP 56. In addition to basic materials in MRS broth, this culture medium includes a set of vitamins, salts, and minerals that provide more suitable conditions for EPS production [48-50]. Centrifugation was employed to extract EPS released into the medium from the supernatant and to separate the capsular EPSs (linked to the cell surface via covalent bond) from the obtained precipitate. In relation to L. plantarum EP 56, capsular polysaccharide has a lower weight than EPS. Grobben et al. (1996) suggested that the regulation of EPS biosynthesis methods in L. bulgaricus 2772 could depend on the carbon source in the culture medium. Growth of this strain in a culture medium containing fructose prevents activation of enzymes that produce EPSs [51].

In general, Tallon et al. studied the amounts of total EPS produced by L. plantarum EP56 at different temperatures on a enriched medium culture with various sugars like galactose, lactose, fructose, and sucrose. They concluded that more polysaccharide was produced at $25^{\circ} \mathrm{C}$ in the presence of lactose, and at the same temperature in the presence of glucose the largest amount of EPS was produced by these bacteria.

\subsubsection{The method for extracting capsular EPS (EPS attached to the wall) by using the Tallon} method.

A single colony from the MRS agar culture medium was removed first using an inoculation loop, cultured on MRS broth, and incubated at $37^{\circ} \mathrm{C}$ for 18,24 , and $48 \mathrm{~h}$ under anaerobic conditions. Ten $\mathrm{ml}$ of the microbial suspension with its turbidity adjusted to that of a $0.5 \mathrm{McFarland}$ standard was then centrifuged at $15,000 \mathrm{~g}$ for $15 \mathrm{~min}$. at $4^{\circ} \mathrm{C}$. Five $\mathrm{ml}$ physiological serum was pipetted onto the obtained precipitate, and the solution was centrifuged again at $15,000 \mathrm{~g}$ for $15 \mathrm{~min}$. at $4^{\circ} \mathrm{C}$. The precipitate was then made viscous by pipetting $5 \mathrm{ml}$ of $0.05 \mathrm{M}$ EDTA on it and was put on a shaker at low speed at $4{ }^{\circ} \mathrm{C}$ for $4 \mathrm{~h}$. It was then centrifuged at $6,000 \mathrm{~g}$ for $30 \mathrm{~min}$. at $4^{\circ} \mathrm{C}$. Two volume of cold ethanol was added to the supernatant and precipitation of the EPS bounded was carried out for $24 \mathrm{~h}$ at $4^{\circ} \mathrm{C}$. To separate the precipitated EPS, centrifugation was used at $6,000 \mathrm{~g}$ for $30 \mathrm{~min}$. at $4^{\circ} \mathrm{C}$. In this stage, the transparent supernatant was discarded and the precipitate containing capsular EPS was dissolved in $2 \mathrm{ml}$ of sterile distilled water to be used for quantitative assessment of capsular 
EPS. To become certain of the results, all experiments were repeated three times [49]. Fig 2 shows the stages in extracting capsular EPS.

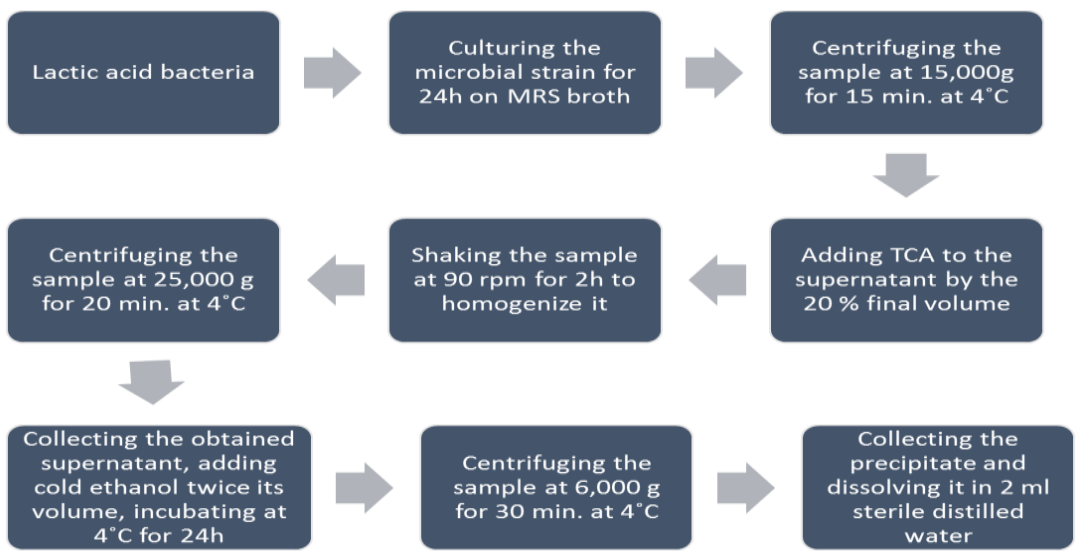

Figure 3. A summary of the Tallon method used for extracting EPS released into the medium.

9.6.1.2. The method for extracting EPS released into the medium by using the Tallon method.

To separate released EPS, first a single colony was removed from the MRS agar using an inoculation loop, cultured on MRS broth, and incubated at $37^{\circ} \mathrm{C}$ for 18,24 , and $48 \mathrm{~h}$ under anaerobic conditions. Ten $\mathrm{ml}$ of the microbial suspension with its turbidity adjusted to that of a $0.5 \mathrm{McFarland}$ standard was then centrifuged at $15,000 \mathrm{~g}$ for $15 \mathrm{~min}$. at $4^{\circ} \mathrm{C}$. The supernatant was treated with TCA with the final concentration of $20 \%$ and incubated at $4{ }^{\circ} \mathrm{C}$ for $2 \mathrm{~h}$. The precipitated proteins were separated by centrifugation at $25,000 \mathrm{~g}$ for $20 \mathrm{~min}$. at $4^{\circ} \mathrm{C}$. Cold ethanol was added twice the volume of the supernatant and kept at $4^{\circ} \mathrm{C}$ for $24 \mathrm{~h}$ for the EPSs to separate from the supernatant and precipitate. Centrifugation was then carried out at $6000 \mathrm{~g}$ for $30 \mathrm{~min}$. at $4^{\circ} \mathrm{C}$, and the obtained precipitate was dissolved in $2 \mathrm{ml}$ water to be used for quantitative assessment of the ESPs produced by intended strain. Fig3 presents summary of stages in EPS extraction using the Tallon method [48].

9.6.2. Extraction of the EPSs released into the medium using the method Bajpai.

Wang et al. (2011) reported that EPS synthesis is a known property of LABs that protects them against adverse environments like drought, toxic materials, and environmental stresses [52].

Bajpai et al. (2016) extracted EPS released into the medium by LABs cultured on broth MRS enriched with glucose $(10 \% \mathrm{w} / \mathrm{v})$. They reported that separation and purification of the EPSs was a time-consuming and expensive method. Nevertheless, extraction of EPSs from LABs attracted interest in the past because they were used as preservatives in the food and pharmaceutical industries and as natural agents for providing natural viscosity and consistency [53].

\subsubsection{The Bajpai method for extracting EPSs released into the medium}

Lactic acid bacterium was cultured at $37^{\circ} \mathrm{C}$ for $18 \sim 24$ hours in MRS modified medium supplemented with $10 \%$ glucose. After centrifugation $\left(8,000 \times \mathrm{g}\right.$ for $20 \mathrm{~min}$ at $\left.4^{\circ} \mathrm{C}\right)$ of culture, the supernatant was collected and added with a final concentration of $14 \%$ trichloroacetic acid to denature the protein content. The culture was further left for homogenization in a shaker $(90$ $\mathrm{rpm}$ ) for 30-40 min followed by centrifugation at $8,000 \times \mathrm{g}$ for $20 \mathrm{~min}$ at $4^{\circ} \mathrm{C}$. The supernatant was then added to cold absolute ethanol (two-fold volume of supernatant) at $4^{\circ} \mathrm{C}$ for 24 hours, 
followed by centrifuge-ation at $8000 \times \mathrm{g}$ at $4^{\circ} \mathrm{C}$ for 20 minutes. These steps resulted in the isolation of crude precipitate. Finally, the precipitate was dissolved in deionized water and dialyzed using Spectra/Por molecularporous tubular dialysis membrane for $24 \sim 48$ hours. The precipitate was then lyophilized in an IIShin freeze dryer (Korea). The freeze-dried lyophilized powder of lactic acid bacterium was considered to be purified exopolysaccharides. The purified exopolysaccharide was stored at $-80^{\circ} \mathrm{C}$ for further analysis [53]. Fig 4 presents a summary of the various stages in the extraction method.

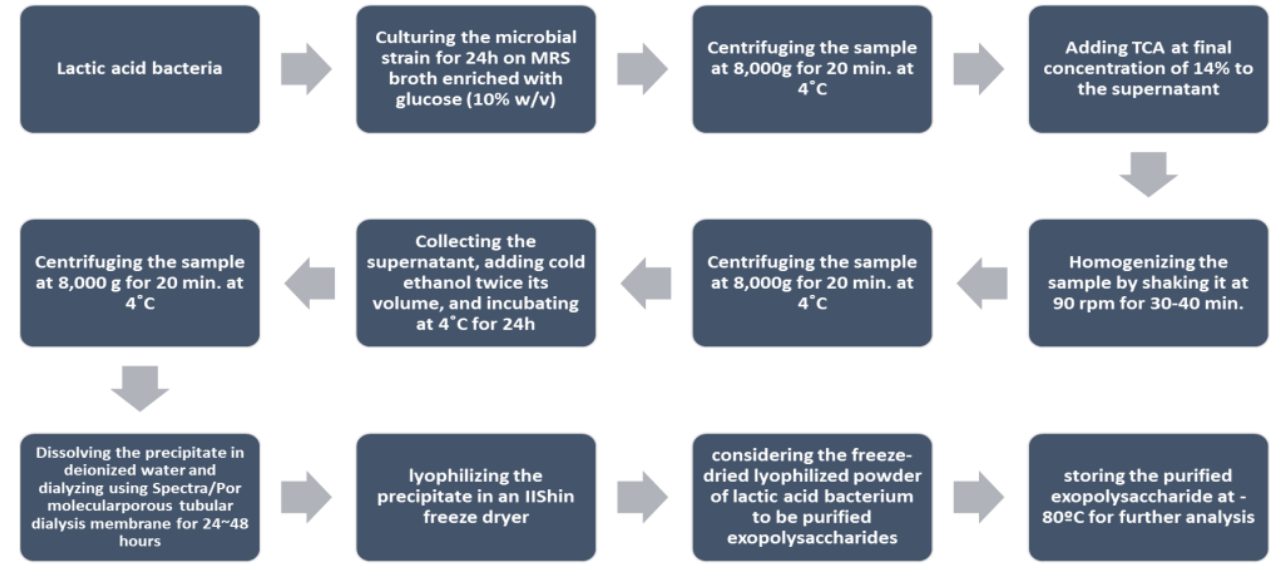

Figure 4. A summary of the method similar to that introduced by Bajpai for extracting EPSs released into the medium.

\subsection{Comparison of biofilm formation in microtiterplate Single culture.}

The ability to construct biofilms is one of the properties of LABs enhancing their resistance to external stresses. As shown in the research, LABs make biofilms of various strengths depending on the type of culture medium and on culturing conditions [45, 24]. In research by Sala-Jara et al. (2016), glucose ( $2 \% \mathrm{w} / \mathrm{v})$ was added to MRS broth to study biofilms made by $L$. fermentum UCO-979 and L. casei Shirota. It was found that L. fermentum formed stronger biofilms than L. casei Shirota. In the article by Salas-Jara et al. (2016), it was stated that biofilm formation by LABs was one of their useful abilities [24].

Some researchers believe that lack of sufficient glucose in a medium causes stress and expression of the genes responsible for preserving life like biofilm construction, which leads to the formation of stronger biofilms. For example, Lebeer et al. (2007) showed that omission of glucose from MRS broth increased the capacity for biofilm construction in L. rhamnosus LGG, whereas the same method yielded the opposite result for L. casei Shirota and a very weak biofilm was formed [15].

In another study, among Lactobacillus strains isolated from dairy products, $L$. acidophilus formed weak biofilms on MRS broth after $24 \mathrm{~h}$, whereas $L$. casei made average biofilms after $24 \mathrm{~h}$. Among 4 strains of L. fermentum on MRS broth under identical conditions, two strains made strong biofilms and the others average biofilms [54]. Tahmourespour and Kermanshahi (2011) examined the effect of Lactobacillus acidophilus DSM 20079 as a probiotic strain on the adhesion of selected streptococcal strains on the surfaces. It was shown that because of bacterial interactions and colonization of adhesion sites with probiotic strain before the presence of streptococci, adhesion reduction of streptococci was observed, so using of probiotics can be an effective way on decreasing cariogenic potential of oral streptococci [55].

\subsection{Mixed cultures.}


Burmolle et al. (2006) stated that most biofilms found in nature included various species coalitions gathered together for one purpose and influenced by interactions like cooperation and interaction or antagonism and competition. Nevertheless, there have been few reports of interactions and relationships between the species in biofilms. Burmolle et al. (2006) showed that Shewanella japonica, Microbacterium phyllosphaerae, Dokdonia donghaensis, and Acinetobacter Iwoffii constructed stronger biofilms when they were together in microplates due to their synergistic interactions compared to their single cultures. They stated that the synergistic interactions caused formation of stronger biofilms compared to the situation in which they exhibited competitive interactions [37]. Aoudia et al. (2016) reported that the probiotic power of L. fermentum increased when it formed biofilms together with other Lactobacilli. Mixed cultures of probiotics are used to treat urinary tract infections [56].

Different strains of a single species that formed weak to average biofilms singly, and various species of a single genus that made biofilms with various strengths singly, were combined and their biofilms were studied to investigate biofilms of isolates and interactions that probiotic bacteria have with each other.

In some isolates, mixed cultures make stronger biofilms, whereas some probiotic strains lack this property due to antagonistic interactions between them.

\section{Conclusions}

In this study, two methods were described to compare these methods and can claim that these two methods were generally suitable for extraction exopolysaccharides from lactobacillus. It must be noted that various factors like culture conditions and type and environmental conditions influence biofilm formation and EPS production, and EPS production is not necessarily the reason for biofilm making by these strains. To prove this claim, further research must be carried out. It is suggested that future research should: Study biofilm construction by isolates on cultures enriched with glucose and Proteose Peptone; Optimize biofilm formation with respect to time, temperature, carbon source, and various $\mathrm{pH}$ values; Investigate biofilm construction by combining more than two bacterial species and strains; Examine biofilm making in other LABs, especially in native isolates; Study effects of the S-layer on biofilm formation; Separate and purify EPSs with higher efficiencies on cultures enriched with various sugars and on enriched cultures like CDM at different temperatures; Investigate genes involved in EPS production and biofilm construction; Examine antimicrobial properties of EPSs extracted from native isolates and determine the structures of their monosaccharides.

\section{Funding}

This research received no external funding

\section{Acknowledgments}

This research has no acknowledgments.

\section{Conflicts of Interest}

The authors declare no conflict of interest. 


\section{References}

1. Massoud, R.; Cruz, A.; Darani, K.K. Ochratoxin A: from safety aspects to prevention and remediation strategies. Current Nutrition \& Food Science $\mathbf{2 0 1 8 ,}$ 14, 11-16, https://doi.org/10.2174/1573401313666170517165500.

2. Zoghi, A.; Khosravi-Darani, K.; Sohrabvandi, S. Surface binding of toxins and heavy metals by probiotics. Mini Reviews in Medicinal Chemistry https://doi.org/10.2174/1389557513666131211105554.

3. Zoghi, A.; Khosravi-Darani, K.; Sohrabvandi, S.; Attar, H.; Alavi S.A. Effect of probiotics on patulin removal from synbiotic apple juice. Journal of the Science of Food and Agriculture 2017, 97, 2601-2609, https://doi.org/10.1002/jsfa.8082.

4. Zoghi, A.; Khosravi-Darani, K.; Sohrabvandi, S.; Attar, H. Patulin removal from synbiotic apple juice using Lactobacillus plantarum ATCC 8014. Journal of Applied Microbiology 2019, 126, 1149-1160, https://doi.org/10.1111/jam.14172.

5. Hadiani, M.R.; Darani, K.K.; Rahimifard, N.; Younesi, H. Biosorption of low concentration levels of Lead (II) and Cadmium (II) from aqueous solution by Saccharomyces cerevisiae: Response surface methodology. Biocatalysis and Agricultural Biotechnology 2018, 15, 25-34, https://doi.org/10.1016-/j.bcab.2018.05.001.

6. Hadiani, M.R.; Khosravi-Darani, K.; Rahimifard, N.; Younesi, H. Assessment of Mercury biosorption by Saccharomyces cerevisiae: Response surface methodology for optimization of low $\mathrm{Hg}$ (II) concentrations. Journal of Environmental Chemical Engineering 2018, 6, 4980-4987, https://doi.org/10.1016/j.jece.2018.07.034.

7. Massoud, R.; Khosravi-Darani, K. Production of synbiotic corn extract: application against diarrhea causing microorganisms. Biointerface Research in Applied Chemistry 2018, 8, 3351-3355,

8. Cerning, J. Production of exopolysaccharides by lactic acid bacteria and dairy propionibacteria. Le Lait 1995, 75, 463-472, https://doi.org/10.1051/lait:19954-536.

9. Sutherland, I. Bacterial exopolysaccharides. Advances in microbial physiology Elsevier 1972, 8, 143-213, https://doi.org/10.1016/S0065-2911(08)60190-3.

10. Reis, J.; Paula, A.; Casarotti, S.; Penna, A. Lactic acid bacteria antimicrobial compounds: characteristics and applications. Food Engineering Reviews 2012, 4, 124-140, https://doi.org/10.1007/s12393-012-9051-2.

11. Boris, S.; Barbés, C. Role played by lactobacilli in controlling the population of vaginal pathogens. Microbes and Infection 2000, 2, 543-6, https://doi.org/10.1016/S1286-4579(00)00313-0.

12. Goudarzi, L.; Kasra, K.R. Antimicrobial activity of different lactobacillus spices in presence of prebiotics against proteus vulgaris. Journal of Mazandaran University of Medical Sciences 2014, 24, 55-64.

13. Behare, P.V.; Singh, R.; Nagpal, R.; Rao, K. Exopolysaccharides producing Lactobacillus fermentum strain for enhancing rheological and sensory attributes of low-fat dahi. Journal of food science and technology 2013, 50, 1228-1232, https://doi.org/10.1007/s13197-013-0999-6.

14. De Vuyst, L.; Degeest, B. Heteropolysaccharides from lactic acid bacteria. FEMS microbiology reviews 1999, 23, 153-177, https://doi.org/10.1111/j.1574-6976.1999.tb00395.x.

15. Lebeer, S.; Verhoeven, T.L.; Vélez, M.P.; Vanderleyden, J.; De Keersmaecker, S.C. Impact of environmental and genetic factors on biofilm formation by the probiotic strain Lactobacillus rhamnosus GG. Applied and Environmental Microbiology 2007, 73, 6768-6775, https://dx.doi.org/10.1128\%2FAEM.0139307.

16. Gupta, P.; Diwan, B. Bacterial exopolysaccharide mediated heavy metal removal: a review on biosynthesis, mechanism and remediation strategies. Biotechnology Reports 2017, 13, 58-71, https://doi.org/10.1016/j.btre.2016.12.006.

17. Korakli, M.; Pavlovic, M.; Gänzle, M.G.; Vogel, R.F. Exopolysaccharide and kestose production by Lactobacillus sanfranciscensis LTH2590. Applied and Environmental Microbiology 2003, 69, 2073-2079, https://dx.doi.org/10.1128\%2FAEM.69.4.2073-2079.2003.

18. Nampoothiri, K.; Beena, D.; Vasanthakumari, D.; Ismail, B. Health benefits of exopolysaccharides in fermented foods. Fermented foods in health and disease prevention, Elsevier 2017, $\mathrm{p}$ 49-62, https://doi.org/10.1016/B978-0-12-802309-9.00003-0.

19. Nácher-Vázquez, M.; Iturria, I.; Zarour, K.; Mohedano, M.L.; Aznar, R.; Pardo, M.Á.; López, P. Dextran production by Lactobacillus sakei MN1 coincides with reduced autoagglutination, biofilm formation and epithelial cell adhesion. Carbohydrate Polymers 2017, 168, 2-31, https://doi.org/10.1016/j.carbpol.2017.03.024. 
20. Costerton, J.W. Introduction to biofilm. International Journal of Antimicrobial Agents 1999, 11, 217-221, https://doi.org/10.1016/s0924-8579(99)00018-7.

21. Belas, R. Biofilms, flagella, and mechanosensing of surfaces by bacteria. Trends in Microbiology 2014, 22 , 517-527, https://doi.org/10.1016/j.tim.2014.05.002.

22. Costerton, J.W.; Stewart, P.S.; Greenberg, E.P. Bacterial biofilms: a common cause of persistent infections. Science 1999, 284, 1318-1322, https://doi.org/10.1126/science.284.5418.1318.

23. Labbate, M.; Queck, S.Y.; Koh, K.S.,; Rice, S.A.; Givskov, M.; Kjelleberg, S. Quorum sensing-controlled biofilm development in Serratia liquefaciens MG1. Journal of Bacteriology 2004, 186, 692-698, https://doi.org/10.1128/jb.186.3.692-698.2004.

24. Salas-Jara, M.; Ilabaca, A.; Vega, M.; García, A. Biofilm forming Lactobacillus: new challenges for the $\begin{array}{llllll}\text { development } & \text { of } & \text { probiotics. } & \text { Microorganisms } & \mathbf{2 0 1 6}, & 4,\end{array}$ https://dx.doi.org/10.3390\%2Fmicroorganisms4030035.

25. Watnick, P.; Kolter, R. Biofilm, city of microbes. Journal of Bacteriology 2000, 182, 2675-2679, https://doi.org/10.1128/jb.182.10.2675-2679.2000.

26. Stickler, D.J.; Morris, N.S.; McLean, R.J.; Fuqua, C. Biofilms on indwelling urethral catheters produce quorum-sensing signal molecules in situ and in vitro. Applied and Environmental Microbiology 1998, 64, 3486-3490.

27. Lepargneur, J.; Rousseau, V. Protective role of the Doderlein flora. Journal de gynecologie, obstetrique et biologie de la reproduction 2002, 31, 485-494.

28. Sarikhani, M.; Kermanshahi, R.K.; Ghadam, P.; Gharavi, S. The role of probiotic Lactobacillus acidophilus ATCC 4356 bacteriocin on effect of HBsu on planktonic cells and biofilm formation of Bacillus subtilis. International Journal of Biological Macromolecules 2018, 115, 762-766, https://doi.org/10.1016/j.ijbiomac.2018.03.087.

29. Khaleghi, M.; Kermanshahi, R.K.; Yaghoobi, M.; Zarkesh-Esfahani, S.; Baghizadeh, A. Assessment of bile salt effects on s-layer production, slp gene expression and some physicochemical properties of Lactobacillus acidophilus ATCC 4356. Journal of Microbiology and Biotechnology 2010, 20, 749-756.

30. Eslami, N.; Kermanshahi, R.K.; Erfan, M. Studying the stability of S-layer protein of Lactobacillus acidophilus ATCC 4356 in simulated gastrointestinal fluids using SDS-PAGE and circular dichroism. Iranian Journal of Pharmaceutical Research 2013, 12, 47.

31. Cheow, W.S.; Hadinoto, K. Biofilm-like Lactobacillus rhamnosus probiotics encapsulated in alginate and carrageenan microcapsules exhibiting enhanced thermotolerance and freeze-drying resistance. Biomacromolecules 2013, 14, 3214-3222, https://doi.org/10.1021/bm400853d.

32. Czaczyk, K.; Myszka, K. Biosynthesis of extracellular polymeric substances (EPS) and its role in microbial biofilm formation. Polish Journal of Environmental Studies 2007, 16.

33. Van Den Berg, D.; Robijn, G.W.; Janssen, A.C.; Giuseppin, M.; Vreeker, R.; Kamerling, J.P.; Vliegenthart, J.; Ledeboer, A.M.; Verrips, C.T. Production of a novel extracellular polysaccharide by Lactobacillus sake 0-1 and characterization of the polysaccharide. Applied and Environmental Microbiology 1995, 61, 28402844.

34. Kleerebezem, M.; Hols, P.; Bernard, E.; Rolain, T.; Zhou, M.; Siezen, R.J.; Bron, P.A. The extracellular biology of the lactobacilli. FEMS Microbiology Reviews 2010, 34, 199-230, https://doi.org/10.1111/j.15746976.2010.00208.x.

35. Tang, J.L.; Gough, C.L.; Daniels, M.J. Cloning of genes involved in negative regulation of production of extracellular enzymes and polysaccharide of Xanthomonas campestris pathovar campestris. Molecular and General Genetics MGG 1990, 222, 157-160, https://doi.org/10.1007/bf00283038.

36. Rendueles, O.; Kaplan, J.B.; Ghigo, J.M. Antibiofilm polysaccharides. Environmental microbiology 2013, 15, 334-346, https://dx.doi.org/10.1111\%2Fj.1462-2920.2012.02810.x.

37. Burmølle, M.; Webb, J.S.; Rao, D.; Hansen, L.H.; Sørensen, S.J.; Kjelleberg, S. Enhanced biofilm formation and increased resistance to antimicrobial agents and bacterial invasion are caused by synergistic interactions in multispecies biofilms. Applied and Environmental Microbiology 2006, 72, 3916-3923, https://doi.org/10.1128/AEM.03022-05.

38. Acid, S.A. Lehninger principles of biochemistry. 2004.

39. McClements, J. Food biopolymers and colloids research laboratory, University of Massachusets Amherst Disponível em:< http://www unix oit umass edu/ mcclemen/581Rheology html> Acesso em 6, 12, 2005. 
40. Dubois, M.; Gilles, K.A.; Hamilton, J.K.; Rebers, P.; Smith, F. Colorimetric method for determination of sugars and related substances. Analytical Chemistry 1956, 28, 350-356, https://doi.org/10.1021/ac60111a017.

41. Sivaraman, T.; Kumar, T.; Jayaraman, G.; Yu, C. The mechanism of 2, 2, 2-trichloroacetic acid-induced protein precipitation, Journal of Protein Chemistry, 16, 291-297, 1997.

42. Rajalingam, D.; Loftis, C.; Xu, J.J.; Kumar, T.K.S. Trichloroacetic acid-induced protein precipitation involves the reversible association of a stable partially structured intermediate. Protein Science 2009, 18, 980-993, https://doi.org/10.1002/pro.108.

43. Christensen, G.D.; Simpson, W.A.; Bisno, A.L.; Beachey, E.H. Adherence of slime-producing strains of Staphylococcus epidermidis to smooth surfaces. Infection and Immunity 1982, 37, 318-326.

44. Shakeri, S.; Kermanshahi, R.K.; Moghaddam, M.M.; Emtiazi, G. Assessment of biofilm cell removal and killing and biocide efficacy using the microtiter plate test. Biofouling 2007, 23, 79-86, https://doi.org/10.1080/08927010701190011.

45. Aoudia, N.; Rieu, A.; Briandet, R.; Deschamps, J.; Chluba, J.; Jego, G.; Garrido, C.; Guzzo, J. Biofilms of Lactobacillus plantarum and Lactobacillus fermentum: effect on stress responses, antagonistic effects on pathogen growth and immunomodulatory properties. Food Microbiology 2016, 53, 51-59, https://doi.org/10.1016/j.fm.2015.04.009.

46. Stingele, F.; Neeser, J.R.; Mollet, B. Identification and characterization of the eps (Exopolysaccharide) gene cluster from Streptococcus thermophilus Sfi6. Journal of Bacteriology 1996, 178, 1680-90, https://doi.org/10.1128/jb.178.6.1680-1690.1996.

47. Lemoine, J.; Chirat, F.; Wieruszeski, J.M.; Strecker, G.; Favre, N.; Neeser, J.R. Structural characterization of the exocellular polysaccharides produced by Streptococcus thermophilus SFi39 and SFi12. Applied and Environmental Microbiology 1997, 63, 3512-3518.

48. Tallon, R.; Bressollier, P.; Urdaci, M.C. Isolation and characterization of two exopolysaccharides produced by Lactobacillus plantarum EP56. Research in Microbiology 2003, 154, 705-712, https://doi.org/10.1016/j.resmic.2003.09.006.

49. Cerning, J.; Bouillanne, C.; Landon, M.; Desmazeaud, M. Isolation and characterization of exopolysaccharides from slime-forming mesophilic lactic acid bacteria.Journal of Dairy Science 1992, 75, 692-699, https://doi.org/10.1016/j.resmic.2003.09.006.

50. Ruas-Madiedo, P. Methods for the screening, isolation, and characterization of exopolysaccharides produced by lactic acid bacteria. Journal of Dairy Science 2005, 88, 853-866, https://doi.org/10.3168/jds.S00220302(05)72750-8.

51. Grobben, G.; Smith, M.; Sikkema, J.; De Bont, J. Influence of fructose and glucose on the production of exopolysaccharides and the activities of enzymes involved in the sugar metabolism and the synthesis of sugar nucleotides in Lactobacillus delbrueckii subsp. bulgaricus NCFB 2772. Applied Microbiology and Biotechnology 1996, 46, 279-284, https://doi.org/10.1007/s002530050817.

52. Wang, C.L.; Huang, T.H.; Liang, T.W.; Fang, C.Y.; Wang. S.L. Production and characterization of exopolysaccharides and antioxidant from Paenibacillus sp. TKU023. New Biotechnology 2011, 28, 559-565, https://doi.org/10.1016/j.nbt.2011.03.003.

53. Bajpai, V.K.; Majumder, R.; Rather, I.A.; Kim, K. Extraction, isolation and purification of exopolysaccharide from lactic acid bacteria using ethanol precipitation method. Bangladesh Journal of Pharmacology 2016, 11, 573-576, https://doi.org/10.3329/bjp.v11i3.27170.

54. Terraf, M.L.; Juárez Tomás, M.; Nader-Macías, M.; Silva, C. Screening of biofilm formation by beneficial vaginal lactobacilli and influence of culture media components. Journal of Applied Microbiology 2012, 113, 1517-1529, https://doi.org/10.1111/j.1365-2672.2012.05429.x.

55. Bujňáková, D.; Kmet', V. Functional properties of Lactobacillus strains isolated from dairy products. Folia Microbiologica 2012, 57, 263-267, https://doi.org/10.1007/s12223-012-0121-x.

56. Tahmourespour, A.; Kermanshahi, R.K. The effect of a probiotic strain (Lactobacillus acidophilus) on the plaque formation of oral Streptococci. Bosnian Journal of Basic Medical Sciences 2011, 11, 37, https://doi.org/10.17305/bjbms.2011.2621.

57. Aoudia, N.; Rieu, A.; Briandet, R.; Deschamps, J.; Chluba, J.; Jego, G.; Garrido, C.; Guzzo, J. Biofilms of Lactobacillus plantarum and Lactobacillus fermentum: effect on stress responses, antagonistic effects on pathogen growth and immunomodulatory properties. Food Microbiology 2016, 53, 51-59, https://doi.org/10.1016/j.fm.2015.04.009. 